\title{
PENGARUH TEKNIK REPEATED READING TERHADAP KEMAMPUAN READING FLUENCY PADA SISWA KELAS III SEKOLAH DASAR
}

\author{
Ila Nurlaila Hidayat \\ Fakultas Psikologi UIN Sunan Gunung Djati Bandung, Jl. A.H Nasution No. 105 Bandung \\ email: ilanurlailahidayat@yahoo.co.id
}

\begin{abstract}
Abstrak
Penelitian dilakukan pada siswa kelas III SD yang belum lancar membaca dengan tujuan peningkatan kemampuan reading fluency. Pendekatan quasi-experimental, single subject randomized time series design dengan treatment teknik repeated reading yang digunakan selama 12 hari. Setiap sessi pengukuran menghasilkan skor WCPM (word correct per minute). Hasil perbandingan Pre-test dan Post-test menunjukkan adanya peningkatan skor WCPM sebesar 15,79. Frekuensi kesalahan dan self-correction semakin menurun serta ekspresi membaca semakin meningkat sering bertambahnya sessi treatment. Teknik repeated reading dapat meningkatkan kemampuan reading fluency subjek.
\end{abstract}

Kata kunci : Teknik repeated reading, reading fluency.

\section{Abstract}

This research was conducted with students of grade III elementary school who are not fluent in reading with the goal to improve their reading fluency. Having quasi-experimental approach with single subject randomized time series design. researcher give repeated reading technique for 12 days. Every measurement session has data in WPCM score (word correct per minute). Comparison between pre-test and post-test show the increasing score of WPCM for 15.79. Error frequency and self-correction are getting decreased while reading expression is getting improved as the treatment session have. Repeated reading technique can improve reading influency.

Keywords : Repeated reading technique, reading fluency.

\section{PENDAHULUAN}

Proses belajar pada setiap tahapan usia akan saling terkait, dimana proses belajar pada tahapan sebelumnya akan mempengaruhi bagaimana proses tersebut pada tahapan usia selanjutnya. Jika dikaitkan dengan jenjang pendidikan dapat diartikan bahwa pendidikan dasar memiliki peran yang sangat signifikan bagi pendidikan selanjutnya. Agar dapat berfungsi secara optimal, idealnya proses belajar yang dilalui di Sekolah Dasar dapat berlangsung secara efektif bagi setiap siswa. Pada kenyataannya efektivitas proses belajar tersebut tidak dapat dicapai sepenuhnya oleh siswa-siswa tertentu karena beberapa hambatan yang dimiliki. Salah satu bentuk hambatan yang seringkali dialami siswa terkait dengan masalah membaca. 
Membaca merupakan hal yang penting dalam proses belajar dan sangat menentukan keberhasilan belajar siswa. Berbagai materi pelajaran lebih banyak disajikan secara tertulis sehingga apabila siswa tidak dapat membaca dengan baik maka ia akan mengalami kesulitan dalam mengikuti kegiatan belajar. Masalah dalam membaca yang terus-menerus akan menghalangi anak untuk menampilkan tugas perkembangan yang mendasar dan menjadi penyebab yang signifikan terhadap tekanan emosi dan gangguan perilaku.

Membaca tidak hanya terbatas pada pengenalan huruf dan mampu untuk mengucapkannya, namun yang lebih utama adalah memahami apa yang dibaca. Smith (1988) ${ }^{1}$ menyatakan bahwa pemahaman adalah kemampuan yang mendasari proses belajar membaca dan proses belajar di hampir semua area pelajaran. Kesulitan dalam memahami bacaan dapat berakibat pada rendahnya minat siswa untuk membaca karena mereka merasa tidak memperoleh manfaat dari membaca. Hal tersebut selanjutnya akan menghambat eksplorasi dan penyerapan informasi pada siswa, sehingga wawasan dan pengetahuan siswa menjadi terbatas.

Salah satu penyebab siswa sulit memahami isi bacaan adalah karena kemampuan membaca yang masih lambat (tidak lancar), sebagaimana diungkapkan oleh para ahli bahwa reading fluency (kelancaran membaca) pada siswa merupakan jembatan antara keterampilan decoding kata dan pemahaman. ${ }^{2}$

Spear-Swerling $(2006)^{3}$ melakukan penelitian yang menunjukan bahwa pemahaman bacaan siswa kelas empat secara signifikan $(42 \%)$ dapat dilihat dari reading fluency siswa saat di kelas sebelumnya. Itu artinya, untuk mencapai

\footnotetext{
${ }^{1}$ Dechant, E. V. 1991. Understanding and Teaching Reading : An Integrative Process. Prentice Hall Inc. New Jersey. Hal.10.

${ }^{2}$ Silbert, 2004.

${ }^{3}$ Spear-Swerling, 2006.
}

pemahaman membaca yang baik, maka siswa harus terlebih dahulu mampu membaca dengan lancar, tepat dan dengan kesalahan yang minimal.

Hasil penelitian PIRLS (2006) tentang pemahaman membaca di kelas 4 sekolah dasar menunjukan rata-rata skor siswa Indonesia adalah 405, di bawah skor internasional yaitu sebesar 500. ${ }^{4}$ Salah satu sebab siswa mengalami kesulitan dalam memahami isi bacaan adalah karena keterampilan mereka dalam membaca yang masih belum lancar, sehingga mereka membutuhkan perhatian lebih besar dalam proses membaca dan mengabaikan perhatian pada pemahaman isi bacaan.

Sebagaimana yang terjadi pada seorang siswa kelas III SD yang berinisial A.S.R., kemampuannya dalam membaca masih berada di bawah kemampuan siswa lain seusianya. Berdasarkan hasil observasi diketahui bahwa saat membaca, subjek masih mengeja kata per kata bahkan per suku kata sehingga menyebabkan tempo membaca menjadi sangat lambat. Selain itu subjek juga seringkali mengabaikan tanda baca yang ditemui sehingga intonasi membaca menjadi datar atau tidak berirama. Adapun kesalahan-kesalahan membaca yang masih terjadi berupa tertukar mengenali huruf yang serupa dari segi bentuk seperti huruf ' $p$ ' menjadi ' $b$ ', ataupun dari segi bunyi; melewatkan huruf ' $n$ ' pada konsonan ganda seperti 'ng' atau 'nt' dan sebagainya; serta pengucapan kata yang tidak tepat.

Mencermati kemampuan membaca subjek sebagaimana diuraikan diatas, dapat disimpulkan bahwa subjek belum memiliki kemampuan reading fluency yang ditandai dengan ketepatan, kecepatan, serta ekspresi saat membaca. Apabila meninjau pendapat lain $^{5}$, dapat dikatakan bahwa subjek masih tergolong ke dalam tipe pembaca kata per kata (word by word reader). Adapun ciriciri dari pembaca kata per kata adalah

\footnotetext{
${ }^{4} \mathrm{http} / / / \mathrm{www}$. trenggalek.com/index.php

${ }^{5}$ Dechant, E. V. 1982. Improving the Teaching of Reading 3rd Ed. Prentice Hall Inc. New Jersey.
} 
membaca dengan lambat, cenderung mengabaikan tanda baca, sering membuat kesalahan dalam membaca frase, membaca dengan nada yang monoton, menunjuk kata-kata dan sering kehilangan kata terakhir yang dibacanya sehingga ada baris yang terlewatkan.

Atas dasar itu peneliti memandang perlu memberikan sebuah treatment berupa teknik repeated reading yang akan diberikan secara berkala untuk meningkatkan reading fluency subjek. Dengan fokus pemberian treatment pada area tersebut terlebih dahulu, diharapkan juga secara bertahap dapat meningkatkan pemahaman membacanya.

\section{Kajian Teori}

Membaca merupakan proses memberikan makna yang dimaksudkan oleh penulis melalui simbol grafis dengan cara menghubungkannya dengan pengalaman seseorang. ${ }^{6}$ Definisi ini mengandung makna bahwa membaca terdiri dari dua proses, yaitu (1) proses pengenalan kata yaitu identifikasi terhadap simbol tertulis (word identification) dan (2) proses asosiasi antara makna dengan simbol tertulis (comprehension). Pada tahap awal, pembaca harus melakukan analisis dengan mencari asosiasi antara simbol visual dengan suara (bunyi) sehingga apa yang dibaca dapat dikenali sebagai suatu kata yang mempunyai bunyi tertentu. Proses ini biasa disebut decoding. Proses ini merupakan dasar yang penting dalam belajar membaca dan merupakan syarat bagi anak untuk masuk ke proses yang kedua.

Pada tahap awal proses membaca, terdapat beberapa bentuk kesulitan atau kesalahan membaca yang umumnya dialami anak yaitu: ${ }^{7}$

\footnotetext{
${ }^{6}$ Dechant, E. V. Improving the Teaching of Reading 3rd Ed. h. 5.

7 Pusat Kurikulum Badan Penelitian dan Pengembangan Departemen Pendidikan Nasional. 2007. Model Kurikulum bagi Peserta Didik yang Mengalami Kesulitan Belajar. h. 5-6.
}

- Penambahan (Addition), yaitu menambahkan huruf pada suku kata

- Penghilangan (Omission), yaitu menghilangkan huruf pada suku kata

- Pembalikan kiri-kanan (Inversion), yaitu membalikan bentuk huruf, kata, ataupun angka dengan arah terbalik kirikanan.

- Pembalikan atas-bawah (Reversal), yaitu membalikan bentuk huruf, kata, ataupun angka dengan arah terbalik atas-bawah.

- Penggantian (Substitution), yaitu mengganti huruf atau angka.

Selain bentuk-bentuk kesalahan diatas, pendapat lain ${ }^{8}$ menambahkan pula kesalahan ucap (mispronunciation), dan ragu-ragu mengucapkan kata lebih dari 3 detik. Adapun sisipan (insertion), mengoreksi diri (self-correction), dan pengulangan (repetition) tidak dinilai sebagai kesalahan.

\section{A. Teknik Repeated Reading}

Metode repeated reading dikembangkan oleh Dahl dan Samuels (1979). Metode ini terdiri dari aktivitas membaca teks yang sama beberapa kali sampai tingkat kecepatan dan ketepatan yang diharapkan tercapai. Hasil dari metode repeated reading adalah peningkatan kecepatan dan ketepatan dalam membaca. Penggunaan metode ini secara berkelanjutan terbukti dapat ditransfer pada materi bacaan yang baru.

Metode repeated reading
dilandasi oleh teori automatic information processing in reading oleh LaBerge \& Samuels. ${ }^{9}$ Menurut teori ini, individu yang dapat memahami bacaan dengan baik adalah mereka yang mampu merekognisi kata dengan otomatis sehingga dapat memfokuskan

\footnotetext{
8 Vaughn, Sharon, Bos, Candace S. 2009. Strategies for Teaching Students with Learning and Behavior Problems : Seventh Edition. New Jersey : Pearson Education. h. 295.

${ }^{9}$ Samuels, S. J. The Method of Repeated Reading.
} 
atensi dan proses berpikirnya untuk memahami isi bacaan. Oleh karena itu, pembaca pemula harus dilatih untuk dapat menguasai kemampuan rekognisi kata dengan otomatis. Repeated reading berfungsi menyediakan latihan bagi pembaca untuk melatih kemampuan rekognisi kata sehingga kecepatan dalam merekognisi kata semakin meningkat sehingga mencapai tingkat otomatis. Kemampuan rekognisi kata yang dapat dikatakan otomatis adalah mampu membaca teks dengan kecepatan sebesar 85 kata per menit. ${ }^{10}$

Dengan memberikan siswa kesempatan untuk membaca berulang kali maka siswa akan melihat dan meninjau kembali kata yang telah ia baca. Ketika siswa membaca kembali teks tersebut, maka ia akan memperbaiki kesalahan yang sebelumnya ia lakukan. Selain itu, dengan pengulangan siswa akan mengingat bunyi kata sehingga kata yang sebelumnya dibaca dengan sulit dan lambat menjadi dibaca dengan lebih mudah dan cepat. Hal ini disebabkan karena terjadi peningkatan unit visual yang mereka olah untuk dapat merekognisi kata. Jika sebelumnya unit visual yang mereka olah adalah huruf per huruf, dengan pengulangan meningkat menjadi kata. Dengan begitu kemampuan rekognisi kata siswa menjadi lebih otomatis.

\section{B. Reading Fluency}

Samuels ${ }^{11}$ mendefinisikan reading fluency sebagai kemampuan untuk mengenal kata dan memahami suatu bacaan pada waktu yang bersamaan. Terdapat 3 komponen dalam reading fluency yaitu:

\footnotetext{
${ }^{10}$ Samuels, S. J. The Method of Repeated Reading.

${ }^{11}$ Samuels, S. J. 2006. Toward a Model of Reading Fluency. Dalam Farstrup, A. E. \& Samuels, S. J. What Research Has to Say About Fluency Instruction, $3 r d \quad E d$. International Reading Association.
}

1. Accuracy of word decoding, merupakan kemampuan untuk mengenali atau mendekode kata-kata secara tepat. Ketepatan decoding direfleksikan melalui kata-kata yang dibaca secara tepat pada tiap kalimat yang diberikan.

2. Automaticity of word recognition, merupakan kemampuan untuk dengan cepat mengenali kata-kata secara otomatis. Kecepatan membaca merefleksikan pemanggilan kata secara otomatis (tanpa pengejaan). Dapat dilihat dari kata-kata yang dibaca dengan benar tiap menit.

3. Prosody of oral text reading, merupakan kemampuan membaca dengan ungkapan yang tepat dan ekspresif, yaitu membaca teks dengan intonasi yang sesuai, tekanan irama yang mempengaruhi pengutaraan tanda baca dalam suatu bacaan.

Penerapan teknik repeated reading dalam penelitian ini yaitu subjek penelitian akan melakukan aktivitas membaca teks yang sama secara berulang hingga 4 kali. Pada setiap kali pengulangan, kepada subjek akan disajikan grafik hasil skor yang ia peroleh. Skor yang dimaksud adalah jumlah kata yang dibaca dengan benar dalam waktu 1 menit dikurangi kesalahan (error) atau dikenal dengan istilah WCPM (word correct per minute). Selanjutnya subjek memperoleh immediate corrective feedback dengan cara meninjau kembali kesalahan-kesalahan membaca lalu bersama-sama memperbaikinya. Melalui urutan proses tersebut akan menstimulasi munculnya proses pengenalan kata (decoding) yang lebih otomatis sehingga kecepatan serta ketepatan mengenali kata dapat meningkat. Selain itu subjek juga akan terkondisi untuk selalu menilai setiap hasil yang ia peroleh (self-evaluation) sehingga hasil tersebut dapat menjadi 
acuan konkret bagi subjek dalam menetapkan target yang ingin ia capai dalam pengulangan maupun sessi berikutnya (goal setting).

Hipotesis yang diajukan adalah "Teknik repeated reading dapat meningkatkan kemampuan reading fluency pada siswa Kelas III SD.

\section{METODOLOGI PENELITIAN}

Penelitian ini menggunakan pendekatan quasi-experimental dengan rancangan single subject randomized time series design ${ }^{12}$ sebagai berikut :

\begin{tabular}{|c|c|}
\hline \multirow{2}{*}{ Pretest } & Posttest \\
\cline { 2 - 2 } & $\mathbf{X}$ \\
\hline \multirow{2}{*}{ Y1Y2Y3Y4 } & Y5Y6Y7Y8Y9Y10Y11Y12Y13Y14Y15Y16 \\
\hline
\end{tabular}

Gambar 3.1 Skema Single Subject Randomized Time Series Design

Variabel bebas adalah teknik repeated reading. Secara konseptual repeated reading adalah sebuah strategi instruksional dimana pembaca membaca satu bagian naskah lebih dari sekali, yang bertujuan untuk memperbaiki otomatisitas pengenalan kata dan menangani pemrosesan level permukaan naskah. ${ }^{13}$

Secara operasional repeated reading adalah melakukan aktivitas membaca teks yang sama secara berulang hingga 4 kali, dimana setiap kali selesai membaca kepada subjek disajikan grafik hasil pencatatan angka WCPM sebagai bahan evaluasi diri (melihat bukti nyata kemajuan dirinya) serta acuan untuk menetapkan target yang lebih tinggi, selanjutnya diberikan immediate corrective feedback terhadap kesalahan-kesalahan selama membaca.

\footnotetext{
${ }^{12}$ Graziano, Anthony M., Raulin, Michael L. 2000. Research Methods A Process of Inquiry: Fourth Edition. Boston: Allyn and Bacon.

${ }^{13}$ Samuels, S. J. 2006. Toward a Model of Reading Fluency. Dalam Farstrup, A. E. \& Samuels, S. J. What Research Has to Say About Fluency Instruction, $3 r d \quad E d$. International Reading Association.
}

Variabel terikat adalah reading fluency. Menurut Samuel, ${ }^{14}$ reading fluency adalah kemampuan untuk membaca teks secara cepat (automaticity of word recognition), akurat (accuracy of word decoding) serta menggunakan ekspresi (prosody of oral text reading).

Secara operasional reading fluency dilihat berdasarkan skor WCPM (Word Correct Per Minute) yang diperoleh dari rata-rata skor 2 trial pada periode pretest serta skor tertinggi dari 4 trial pada periode posttest.

Adapun relevant variable yang dipertimbangkan adalah:

a. Controlled Variable

1) Waktu. Pengukuran selama 16 hari, dilakukan pada waktu yang sama yaitu pukul 17.00 WIB.

2) Situasi ruangan. Menggunakan ruangan kelas dengan situasi nyaman, pencahayaan cukup, dan terhindar dari keributan.

3) Bahan bacaan. Memiliki bobot sama dari segi jenis (teks narasi fiksi), kesesuaian dengan tingkat pendidikan (bersumber dari buku Bahasa Indonesia Kelas III SD) ${ }^{15}$, maupun jumlah kata (kurang lebih 50 kata).

b. Uncontrolled Variable

1) Kondisi kesehatan, yaitu kemungkinan subjek mengalami kondisi sakit.

2) Konsentrasi, yaitu kemungkinan terjadinya tingkat konsentrasi berbeda pada setiap pengukuran, yang mungkin dipengaruhi oleh aktivitas subjek sebelumnya.

Subjek penelitian merupakan partisipan tunggal dengan karakteristik : laki-laki berusia 9 tahun; siswa Kelas III $\mathrm{SD}$; termasuk tipe pembaca kata per kata (word by word reader); dan belum pernah mendapatkan treatment.

\footnotetext{
${ }^{14}$ Samuels. Toward a Model of Reading Fluency.

15 Sulistyaningsih, Mei. 2007. Bahasa Indonesia Untuk SD \& MI Kelas III. Jakarta : Pusat Perbukuan Departemen Pendidikan Nasional.
} 
Alat ukur berupa bahan bacaan jenis teks narasi fiksi, dengan prosedur sebagai berikut:

a. Memilih 2 bahan bacaan dan menyiapkan 2 buah salinan untuk setiap bahan bacaan : salinan pertama untuk menandai kesalahan-kesalahan, salinan kedua digunakan subjek untuk membaca.

b. Menyiapkan stopwatch dan alat perekam

c. Memberikan instruksi : "Ketika saya katakan 'mulai', mulailah membaca dengan suara keras. Bacalah sebaik mungkin, jika menemukan kata yang asing, saya akan memberi tahu". Jika subjek tidak membaca suatu kata dalam 3 detik, peneliti melafalkan kata tersebut.

d. Subjek membaca dalam waktu 1 menit. Sambil mengikuti bacaan siswa, peneliti menandai salinannya dengan membubuhi tanda garis miring (/) pada kata-kata yang salah dibaca, meliputi mispronunciation, substitution, omission, ragu-ragu mengucapkan kata lebih dari 3 detik, reversal, dan addition. Adapun sisipan (insertion), mengoreksi diri (self-correction), dan pengulangan (repetition) tidak dihitung sebagai kesalahan.

e. Peneliti juga mencatat apakah subjek memiliki kesulitan dengan pengungkapan : mengabaikan tanda baca; membaca lambat, kata demi kata/kerja keras; dan sering berhenti lama, salah memulai, pengulangan.

Cara skoring dilakukan dengan menghitung angka WCPM (word correct per minute) berdasarkan jumlah kata yang dibaca dengan benar dalam 1 menit dikurangi jumlah kesalahan.

Pengolahan data dalam penelitian ini menggunakan statistik deskriptif berupa penyajian data hasil penelitian dalam bentuk grafik. Teknik analisis ini dipilih sesuai dengan rancangan penelitian, dimana subjek penelitian hanya terdiri dari 1 orang. Penarikan kesimpulan mengenai hipotesis penelitian dilihat berdasarkan ada tidaknya kenaikan grafik dari kondisi pretest menuju posttest.

\section{HASIL PENELITIAN DAN PEMBAHASAN}

Hasil pengolahan data dapat disajikan dalam beberapa grafik sebagai berikut :

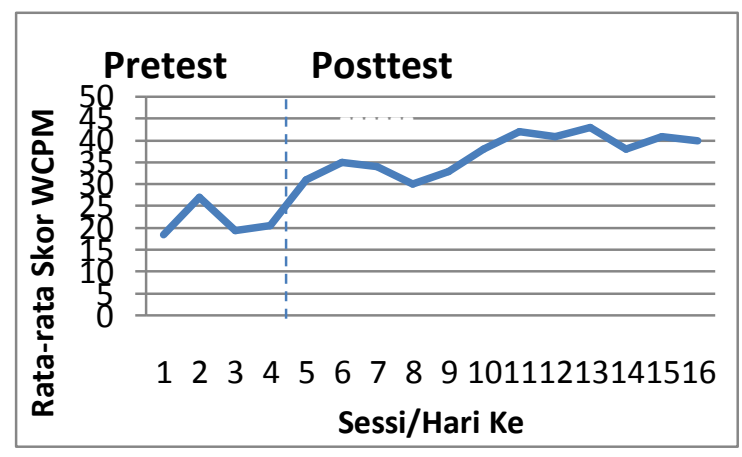

Gambar 4.1. Perolehan rata-rata skor WCPM pada kondisi pretest dan posttest

Berdasarkan grafik tersebut dapat dilihat bahwa dalam rentang waktu 16 hari pengukuran, pola umum grafik secara konsisten menunjukan terjadinya kenaikan pada sebagian besar pengukuran dari waktu ke waktu.

Meskipun pada dua kondisi tersebut sama-sama terjadi kenaikan skor, namun dapat dibedakan secara nyata perbedaan dalam pola kenaikan skornya. Pada pretest (dengan mengabaikan skor ekstrem), dapat dilihat bahwa pola kenaikan berjalan secara lambat yaitu sebesar 1 poin. Kenaikan sebesar 1 poin dapat dianggap kurang signifikan karena bisa jadi hal itu berasal dari ketidakseimbangan panjang/pendeknya kata yang terdapat dalam bacaan. Sedangkan pada posttest, kenaikan skor berlangsung lebih progresif yaitu berkisar antara 2 hingga 5 poin. Selain itu dapat dilihat pula selisih angka sebesar 12 poin dari skor terendah 31 serta skor tertinggi 43. Dengan demikian pemberian treatment dalam jangka waktu 12 hari telah membuktikan adanya peningkatan kemampuan reading fluency. 
1. Gambaran lengkap periode pretest

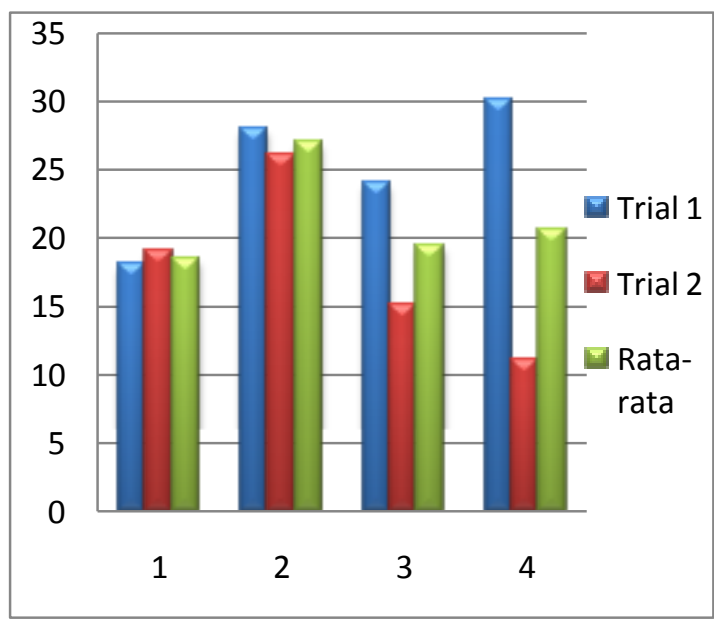

Gambar 4.2. Perolehan skor WCPM pada kondisi pretest

Pada periode pretest, angka rata-rata selama 4 hari menunjukan kenaikan setiap kali pengukuran, artinya hasil pengukuran hari kedua, ketiga dan keempat tidak ada yang lebih rendah dari hari pertama. Adapun hasil pengukuran hari ketiga yang secara nyata terlihat turun, pada dasarnya lebih tepat dinilai bahwa hari kedua yang mengalami kenaikan cukup tajam yaitu sebesar 8.5 poin. Peneliti menyimpulkan hal itu berkaitan dengan kata-kata yang terdapat dalam bacaan telah familiar bagi subjek. Hal ini terbukti dari paling sedikitnya jumlah kesalahan membaca yaitu 2 poin, dibandingkan tiga hari lainnya yaitu 3,5 , dan 4 poin (lihat gambar 4.4).

Pada periode pretest, rata-rata skor yang diperoleh dari 4 kali pengukuran adalah 21.38. Angka tersebut menggambarkan kondisi awal kemampuan reading fluency subjek. Pada periode ini, saat membaca subjek mengenali kata secara huruf per huruf, sehingga untuk membaca satu kata saja memerlukan waktu yang lama. Demikian halnya pada saat diberikan bacaan baru, proses pengenalan kata oleh subjek masih berlangsung seperti semula (huruf per huruf). Proses membaca seperti itu cukup menyulitkan terbentuknya otomatisasi, terbukti dari skor perhari, dimana skor trial 2 justru lebih rendah dibanding trial 1, kecuali pada hari pertama trial 2 meningkat satu kata (lihat gambar 4.2). Lalu adanya penambahan beberapa kata dari setiap sessi tidak berarti mengindikasikan telah terbentuknya proses otomatisasi, melainkan berkaitan dengan panjang/pendeknya kata setiap berganti bacaan.

2. Gambaran lengkap periode posttest

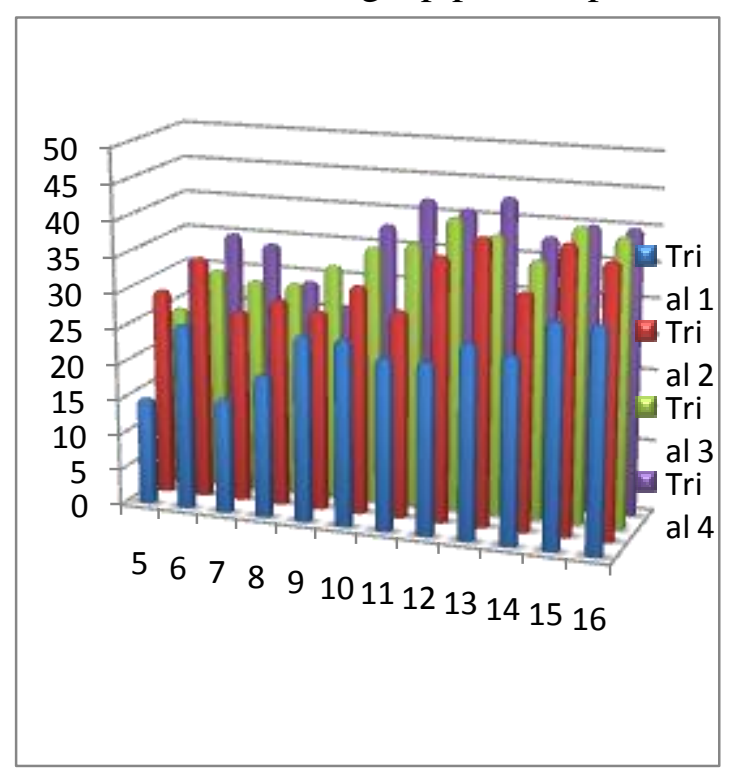

Gambar 4.3. Perolehan skor WCPM pada kondisi posttest

Pada periode posttest perolehan skor WCPM subjek secara gradual menunjukan peningkatan baik pada setiap kali trial, maupun pada setiap sesi. Adapun penurunan grafik hanya terjadi pada hari ke-4 (sessi 8) dan ke-10 (sessi 14) yaitu sebesar 4 dan 5 poin, dimana pada hari tersebut subjek sedang dalam kondisi kurang sehat. Hal ini menunjukan bahwa proses decoding atau pengenalan kata pada subjek secara bertahap telah mengalami otomatisasi.

Melalui pengulangan dalam teknik repeated reading subjek dapat mengingat bunyi kata sehingga kata yang sebelumnya dibaca dengan sulit dan lambat menjadi dibaca dengan lebih mudah dan cepat. Hal 
ini disebabkan oleh terjadinya peningkatan unit visual yang ia olah. Jika sebelumnya unit visual yang diolah adalah huruf per huruf, maka meningkat menjadi kata. Dengan begitu kemampuan mengenal kata subjek menjadi lebih otomatis.

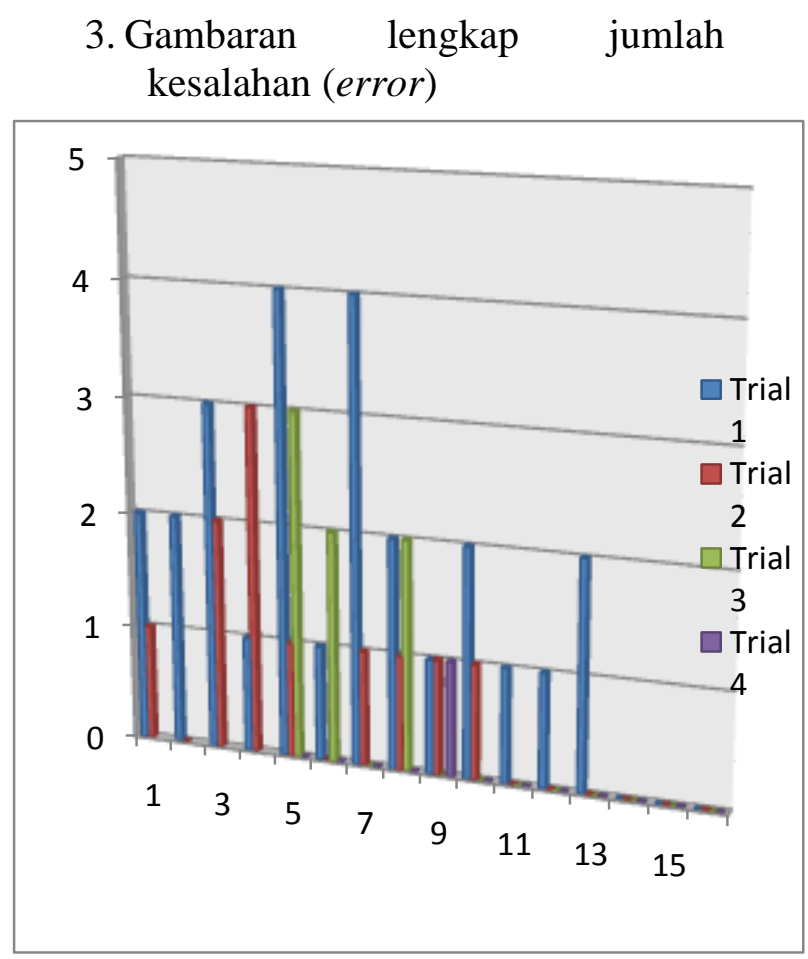

Gambar 4.4. Jumlah kesalahan (error) pada kondisi pretest dan posttest

\section{Gambaran lengkap jenis-jenis kesalahan (error)}

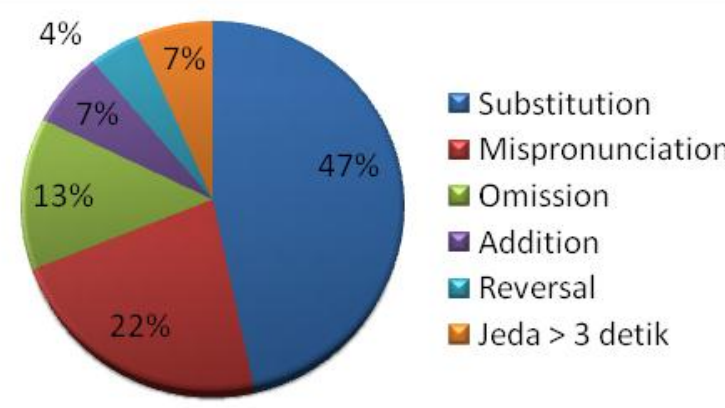

Gambar 4.5. Prosentase total kesalahan (error) berdasarkan jenisnya
Setiap kali selesai membaca, peneliti menyajikan grafik hasil membaca berisi skor WCPM yang diperoleh dari jumlah kata yang dibaca benar dalam waktu 1 menit dikurangi jumlah kesalahan. Penyajian grafik seperti ini terbukti dapat memberikan efek motivasional, dimana subjek dapat melakukan evaluasi diri dengan melihat secara langsung hasil kemajuannya sehingga ia juga dapat menyusun target (goal setting) untuk mencapai hasil yang lebih baik lagi.

Selanjutnya pemberian immediate corrective feedback (meninjau kembali kesalahan-kesalahan yang dilakukan lalu bersama-sama memperbaikinya) pada setiap kali pengulangan, terbukti pula dapat mengurangi kesalahan-kesalahan dalam membaca. Frekuensi kesalahan semakin berkurang seiring dengan meningkatnya trial maupun sesi. Dalam 12 sessi treatment tercatat jumlah kesalahan sebesar 31 kata. Dari jumlah tersebut, kesalahan mencapai hingga $87.1 \% \quad$ (27 kata) pada 6 hari pertama, sedangkan 6 hari terakhir hanya $12.9 \%$ (4 kata). Bahkan pada 3 hari terakhir subjek sama sekali tidak melakukan kesalahan. Apabila meninjau jenis kesalahan membaca, subjek paling sering mengganti satu atau beberapa huruf dalam satu kata (substitution). Pada beberapa kata tertentu seperti 'tidak' ataupun kata yang mengandung huruf vokal 'e', subjek belum dapat melafalkan kata secara tepat (misspronunciation). Pada kata-kata yang mengandung konsonan ganda, terkadang masih ada satu huruf yang hilang atau terlewat (omission). Bentuk-bentuk kesalahan lain yang sesekali masih muncul adalah penambahan huruf (addition), ragu-ragu melafalkan kata lebih dari 3 detik serta pembalikan huruf atas-bawah (reversal).

Saat membaca, subjek juga masih sering melakukan koreksi sendiri (selfcorrection) terhadap kata-kata yang salah dibaca. Meskipun tidak dihitung sebagai kesalahan, namun tentunya cukup berpengaruh terhadap kecepatan membaca, 
karena mengoreksi membutuhkan waktu lebih lama. Meski demikian pola selfcorrection inipun menunjukan penurunan yaitu 14 kali $(66.7 \%)$ pada 6 hari pertama, dan berkurang menjadi 7 kali $(33.3 \%)$ pada 6 hari terakhir. Selain itu berkaitan dengan aspek ekspresi (prosody) dalam membaca, subjek yang pada mulanya membaca dengan intonasi datar atau monoton akibat mengabaikan tanda baca, telah menunjukan kemajuan secara bertahap sehingga bacaan subjek terdengar lebih berirama sesuai dengan tanda baca yang ada.

\section{SIMPULAN DAN SARAN}

Berdasarkan analisa hasil, maka diperoleh beberapa kesimpulan sebagai berikut :

1. Teknik repeated reading yang diberikan kepada seorang siswa Kelas III SD dengan tipe pembaca kata per kata terbukti dapat meningkatkan kemampuan reading fluency subjek.

2. Pemberian teknik repeated reading selama 12 hari dengan 4 kali pengulangan terbukti dapat meningkatkan skor WCPM sebesar 15.79 dari rata-rata skor sebelum treatment 21.38 menjadi 37.17 setelah treatment.

3. Frekuensi beragam kesalahan membaca maupun self-correction semakin menurun serta kemampuan membaca ekspresif meningkat seiring dengan bertambahnya sessi treatment. adalah :

Saran-saran yang dapat diberikan

1. Teknik repeated reading sebaiknya diterapkan saat siswa mulai duduk di kelas I SD, agar reading fluency terbentuk lebih awal guna memudahkan mereka mencapai tingkat pemahaman saat membaca.

2. Jumlah trial maupun sessi repeated reading dapat ditingkatkan kembali agar proses otomatisasi dan akurasi pengenalan kata berlangsung lebih efektif lagi.

3. Bagi guru dan terutama orang tua, dapat menerapkan teknik ini secara berkelanjutan, agar motivasi anak senantiasa terjaga untuk menghadapi setiap bahan bacaan baru.

\section{DAFTAR PUSTAKA}

Azwar, Saifuddin. 2000. Reliabilitas dan Validitas. Yogyakarta: Pustaka Pelajar.

Dechant, Emerald V. 1982. Improving the Teaching of Reading, Third Edition. New Jersey: Prentice-Hall Inc.

Dechant, E. V. 1991. Understanding and Teaching Reading : An Integrative Process. Prentice Hall Inc. New Jersey.

DeRuiter, J. A. \& Wansart, W. L. 1982. Psychology of Learning Disabilities: Applications and Educational Practices. London: Aspen Systems Corporation.

Harris, A. J. \& Sipay, E. R. 1980. How to Increase Reading Ability : A Guide to Developmental and Remedial Methods 7th Ed. Longman, Inc. New York.

Kumara, A. 2010. Mengasah Keterampilan Membaca pada Anak Melalui Belajar atau Bermain, Fakultas Psikologi Universitas Gadjah Mada.

Masjidi, Noviar. 2007. Agar Anak Suka Membaca : Sebuah Panduan bagi Orang Tua. Yogyakarta : Media Insani. 
Graziano, Anthony M., Raulin, Michael L. 2000. Research Methods A Process of Inquiry : Fourth Edition. Boston: Allyn and Bacon.

Pusat Kurikulum Badan Penelitian dan Pengembangan Departemen Pendidikan Nasional. 2007. Model Kurikulum bagi Peserta Didik yang Mengalami Kesulitan Belajar.

Rief, Sandra F., Stern, Judith M. 2010. The Dyslexia Checklist: A Practical Reference for Parents and Teachers. USA : Jossey-Bass.

Samuels, S. J. 1979. The Method of Repeated Reading. The Reading Teacher.

Samuels, S. J. 2002. Reading Development: Its Development and Assesment. Dalam Farstrup, A. E. \& Samuels, S. J. What Research Has to Say About Reading Instruction, 3rd Ed. International Reading Association.

Samuels, S. J. 2006. Toward a Model of Reading Fluency. Dalam Farstrup, A. E. \& Samuels, S. J. What Research Has to Say About Fluency Instruction, $3 r d E d$. International Reading Association.
Smith. N.A. \& Robinson, H.A. 1980. Reading Instruction for Today's Children 2nd Ed. Prentice Hall Inc. New York.

Sulistyaningsih, Mei. 2007. Bahasa Indonesia Untuk SD \& MI Kelas III. Jakarta : Pusat Perbukuan Departemen Pendidikan Nasional.

Tankersley, Karen. 2003. The Threads of Reading : Strategies for Literacy Development. USA : Association for Supervision and Curriculum Development.

Tedick, D., Gortari, B. 1998. Research on Error Correction and Implications for Classroom Teaching. The Bridge, ACIE Newsletter. Center for Advanced Research on Language Acquisition, University of Minnesota, 1 .

Vaughn, Sharon, Bos, Candace S. 2009. Strategies for Teaching Students with Learning and Behavior Problems : Seventh Edition. New Jersey: Pearson Education.

http://www.trenggalek.com/index.php 